6. Butkova, O. I., Latysheva, Z. M., Silina, L. P. (2006). Rol' bakterial'nyh infekcij v patogeneze vnutrimatochnoj gibeli ploda. Reproduktivnoe zdorov'e zhenshhiny, 4(29), 95-98.

7. Veropotveljan, P. M., Veropotveljan, M. P., Goruk, P. S. (2009). Zavmerla vagitnist' u pacijentok zi zvychnym vykydnem imunomorfologichni zminy v decydual'nij tkanyni pry hlamidijnij infekcii'. Pediatryja, akusherstvo ta ginekologija, 6, 59-61.

8. Podzolkova, N. M., Skvorcova, M. L., Mel'nikova, N. I. (2009). Vnutriutrobnaja infekcija: sovremennoe sostojanie problemy. Akusherstvo i ginekologija, 3, 27-32.

9. Krasnopol'skij, V. I., Serova, O. F., Tumanova, V. A. et. al. (2004). Vlijanie infekcij na reproduktivnuju sistemu zhenshhin. Rossijskij vestnik akushera ginekologa, 5, 26-28.
10. Chajka, V. K., Demina, T. N., Goshkoderja, I. Ju. (2005). Sostojanie gormonal'nogo statusa i receptornogo apparata jendometrija u zhenshhin s hronicheskim vospaleniem genitalij. Zdorov'e zhenshhiny, 2,66-70.

11. Lecce, G. (2001). Presence of Estrogen Receptor in the Human Endometrium through the Cycle: Expression in Glandular, Stromal, and Vascular Cells. Journal of Clinical Endocrinology \& Metabolism, 86 (3), 1379-1386. doi: 10.1210/ jc.86.3.1379

12. Carp, H., Torchinsky, A., Fein, A., Toder, V. (2001). Hormones, cytokines and fetal anomalies in habitual abortion. Gynecological Endocrinology, 15 (6), 472-483. doi: 10.1080/ gye.15.6.472.483

Дата надходження рукопису 14.04.2015

Тищенко Александра Николаевна, ассистент, кандидат медицинских наук, кафедра нормальной физиологии, Харьковский национальный медицинский университет, пр. Ленина, 4, г. Харьков, Украина, 61022 E-mail:alexandra.tish@mail.ru

Юркова Ольга Валентиновна, ассистент, кандидат медицинских наук, кафедры акушерства и гинекологии № 1, Харьковский национальный медицинский университет, пр. Ленина, 4, г. Харьков, Украина, 61022 E-mail:alexandra.tish@mail.ru

Лазуренко Виктория Валентиновна, доктор медицинских наук, профессор, кафедра акушерства и гинекологии № 1, Харьковский национальный медицинский университет, пр. Ленина, 4, г. Харьков, Украина, 61022 E-mail:lazur13@mail.ru

\title{
УДК: 616.711+616.832-06-036.4-089-092.4
}

DOI: 10.15587/2313-8416.2015.43100

\section{МАГНИТНО-РЕЗОНАНСНАЯ ТОМОГРАФИЯ ПОЗВОНОЧНО-СПИННОМОЗГОВОЙ ТРАВМЫ В ОСТРОМ И РАННЕМ ПЕРИОДАХ}

\section{(C) Н. Н. Сальков}

Актуальность темы обусловлена необходимостью оптимизацчи диагностического поиска у пацичентов с позвоночно-спинномозговой травмой, визуализации повреждений спинного мозга, вторичньх изменений, используя МРТ исследования. Проведено стандартное МРТ исследования пораженного отдела позвоночника у 24 пациентов, из которых травма в шейном отделе отмечалась у 11 пациентов, в грудном отделе - в 13. исследовании проводилось в сроки от 1 до 18 дней в режимах Т1 и Т2 ВИ в ИП SE Ключевые слова: позвоночно-спинномозговая травма, магнитно-резонансная томография, отек

The topic actuality is conditioned upon the necessity to optimize the diagnostic detection in patients with spinal injury, imaging of spinal medulla damage, secondary alterations with the help of MRI examination. Standard magnetic resonance imaging examination of the patients was performed to diagnose the prevalence rate of ischemia and edema. According to previously published studies, the main factors in the pathogenesis of spinal cord injury are attributed to primary and secondary mechanism. Primary spinal cord injury occurs at the time of the initial trauma or damage, forming a zone of spinal cord contusion. Disorders can be found in the local vasculature, causing edema and hemorrhage. Paralysis of motor, sensory and autonomic neuronal functions can occur in the damaged area. Vascular dysfunction, ischemia, glutamatergic excitotoxicity, inflammation and apoptosis also develop in the perifocal zone.

Methods. There was carried out standard MRI examination of the affected region of vertebral column in 24 patients, 11 patients of which has trauma in cervical area and 13 - in thoracic part. The examination was carried out within the term from 1 to 18 days, in the modes T1 and T2 WI in IS SE. To standardize the study there was defined extension of edema or signal change in the medullary substance, level of spinal medulla compression. Results. The study is carried out on the following day after trauma and it is defined the site of injury, hemorrhachis and medullary substance edema site in the area of initial injury within the measures of 1-2 segments of spinal medulla. MRI of 2-13 days shows increased distribution of hemorrhachis and medullary substance edema within 4-5 segments of spinal medulla, evidencing globalization of secondary alteration of spinal medulla. 
Conclusions. Magnetic resonance imaging is the leading method in the diagnosis of swelling of the spinal cord injury and hemorrhage. Secondary changes in the spinal cord are revealed during the study. The method allows visualizing the extent and severity of damage to the spinal cord, hence the importance of the method in the initial phase of treatment, patients with spinal cord injury

Keywords: spinal injury, magnetic resonance imaging, edema

\section{1. Введение}

Магнитно-резонансная томография (МРТ) является ведущим исследованием в диагностике повреждений спинного мозга и единственным, позволяющим визуализировать спинной мозг. МРТ позволяет выявить компрессию спинного мозга костными структурами, фрагментами дисков, связок, подсвязочную и экстрадуральную гематому. Метод позволяет классифицировать травму, разработать тактику лечения, уточнить особенности повреждения: наличие гематомы, отека и ишемии компрессию спинного мозга, гематомиелию и очаг ушиба, максимальную компрессию спинного мозга, максимальную компрессию позвоночного канала, протяженность отека и ишемии, протяженность и объем очага ушиба и гематомиелии, повреждение связочного аппарата позвоночника, позвонков и межпозвонковых дисков.

Это обусловливает важность метода на начальном этапе лечения пациентов с позвоночно-спинномозговой травмой [1-3].

Целью работы является изучение диагностической ценности метода, визуализации развития вторичных изменений спинного мозга у пациентов с позвоночно-спинномозговой травмой в остром и раннем периодах.

\section{2. Обоснование исследования}

В научной литературе не найдено информационных источников диагностики формирования развития вторичных изменений спинного мозга позвоночной и позвоночно-спинномозговой травмы. Магнитно-резонансная томография является предпочтительным исследованием определения отека спинного мозга, ушиба, гематомиелии, кровоизлияния $[1,2]$.

Проведение исследования через 24 часа с момента травмы, позволяет выявить развитие вторичных изменений (отека) в спинном мозге [2]. Метод позволяет визуализировать протяженность и выраженность повреждения спинного мозга, что обусловливает важность метода на начальном этапе лечения пациентов с позвоночно-спинномозговой травмой [3].

\section{3. Материалы и методы исследований}

С января 2013 г. по октябрь 2014 г., в КУ «Областная клиническая больница им. И. И. Мечникова» г. Днепропетровска. С целью диагностики состояния мозгового вещества, компрессии спинного мозга, объема и распространенности отека нами проведено стандартное МРТ исследование пораженного отдела позвоночника у 24 пациентов, из которых, травма в шейном отделе отмечалась у 11 пациентов, в грудном отделе у 13. Исследования проводились в сроки от 1 до 18 дней, в режимах Т1 и Т2 ВИ в ИП SE. Невро- логический дефицит по шкале ASIA соответствовал А - С. Возраст пациентов соответствовал 18-70 лет. В 22 случаях произведена декомпрессивно-стабилизирующая операция. Два пациента не прооперированы. Из них 10 пациентов было прооперировано в течение первых 3-х суток, а 12 в период между 3 и 6 сутками.

Интенсивная терапия у пациентов с позвоночно-спинномозговой травмой была направлена на 4 патогенетических механизма:

1) сосудидистых расстройств - нарушение сосудистой ауторегуляции, вазоспазма, тромбоза;

2) электролитного дисбаланса, энергетического метаболизма, отека;

3) глутаматэргической эксайтотоксичности, накопления свободных радикалов, перекисного окисления липидов;

4) замедление клеточного некроза и апоптоза.

Наряду с местными изменениями мозгового вещества, в процесс запускается каскад механизмов вызывающих кардио-пульмональную дисфункцию, изменение фибринолитической активности крови, которые представляют реальную угрозу жизни пациента, а также являются порочным кругом, усиливающим вторичные изменения спинного мозга. Ограничение к проведению исследования составляла группа больных с нарушением витальных функций, тяжелой сочетанной травмой.

\section{4. Результаты исследования и их обсуждение}

МРТ исследование, выполненное в 1-е сутки после травмы (8 пациентов), позволяет визуализировать очаг ушиба, гематомиелии и зону отека мозгового вещества в области первичного повреждения, в пределах 1-2 сегментов спинного мозга. В Т1 ВИ, кровоизлияние характеризовалось изоинтенсивным сигналом, но в Т2 ВИ определялся гиперинтенсивный сигнал (рис. 1, 2).

Проведение МРТ на 2-13 сутки (16 пациентов), показывает увеличение распространенности гематомиелии, ишемии и отека на протяжении 4-5 сегментов спинного мозга, что свидетельствует о глобализации вторичных изменений спинного мозга.

Зона отека - ишемии была выявлена во всех наблюдениях, которая на Т1 ВИ, выглядела изоинтенсивной нормальному спинному мозгу, на Т2 ВИ имела гиперинтенсивный сигнал, убывающий от центра очага к периферии. Кровоизлияниие обнаружено в 5 случаях. На Т2 ВИ кровоизлияние соответствовало гиперинтенсивному сигналу в центре, которого отмечался гипоинтенсивный МРТ - сигнал, в Т1 ВИ вследствие образования оксигемоглобина, который обладает парамагнитными свойствами, сигнал переходит в гиперинтенсивную форму. В 4-х наблюдениях экстрадуральная гематома находилась между телом позвонка и задней продольной связкой. Выявить подсвязочное расположе- 
ние гематомы помогали срезы в аксиальной проекции, так как, задняя продольная связка плотно прилежит к задней поверхности тела позвонка и твердой мозговой оболочке и на сагиттальных срезах четко не контурируется. Отсутствие анатомического повреждения связки подтверждалось визуализацией на операции (рис. 3, 4).

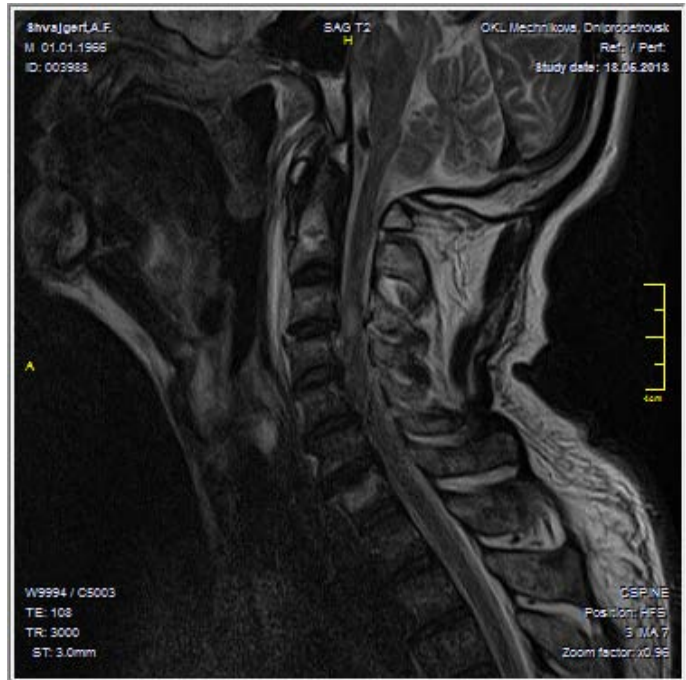

Рис. 1. МРТ исследование в Т2 ВИ, выполненное в 1-е сутки травмы. Определяется очаг ушиба и перифокальная зона отека на уровне С3-C4

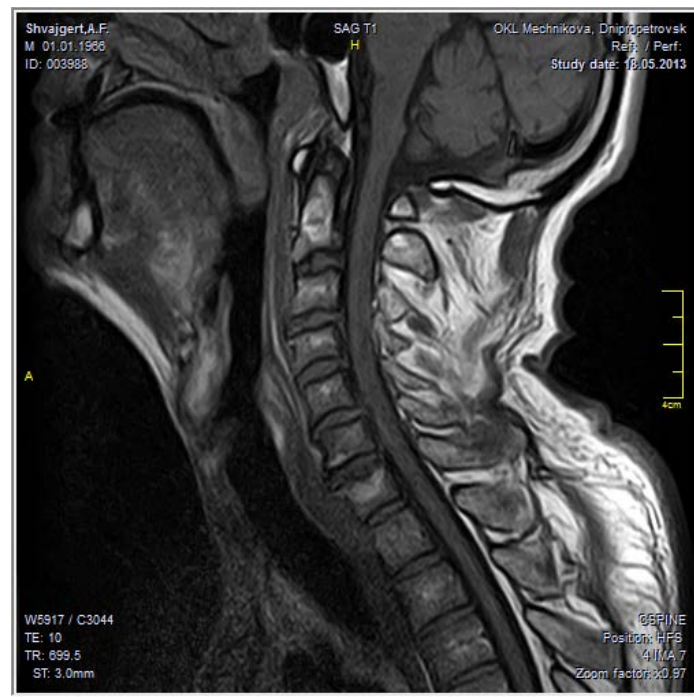

Рис. 2. МРТ исследование в Т1 ВИ, выполненное в 1-е сутки травмы. Определяется перифокальная зона отека на уровне C3-C4

Очаг ушиба отмечался во всех наблюдениях и проявлялся на Т2 ВИ гиперинтенсивным сигналом с изоинтесивным участком в центре и на Т1 ВИ был изоинтенсивным. Важным являлось динамическое проведение МРТ исследования, что позволяло оценивать степень распространения вторичных изменений спинного мозга и тем самым влияло на тактику лечения пациента.

Показательным является следующее наблюдение.

(Пациент Ж.), 18 лет, поступил в отделение хирургии позвоночника и спинного мозга областной клинической больницы им. И.И. Мечникова с жало- бами на отсутствие движений и чувствительности в руках и ногах, туловище.

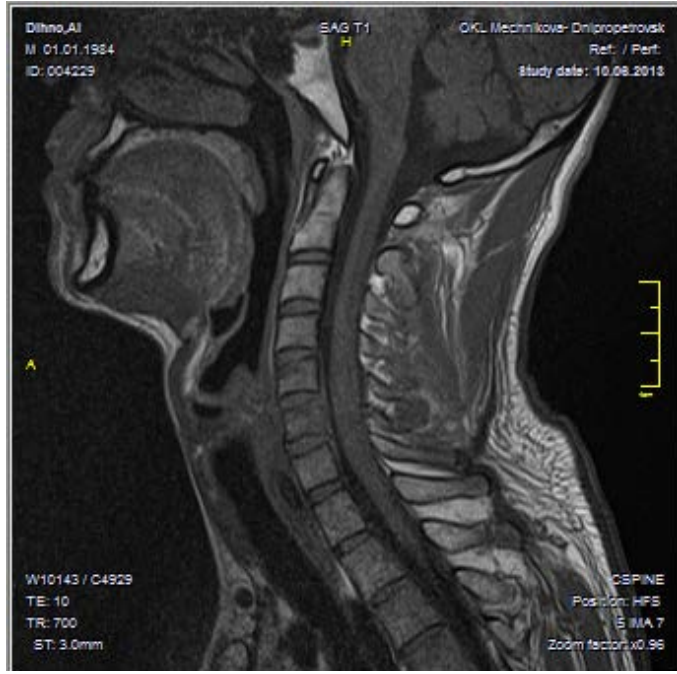

Рис. 3. МРТ исследование в Т1 ВИ, выполненное на 2-е сутки травмы. Отмечается гематома над задней продольной связкой на уровне С5-C7

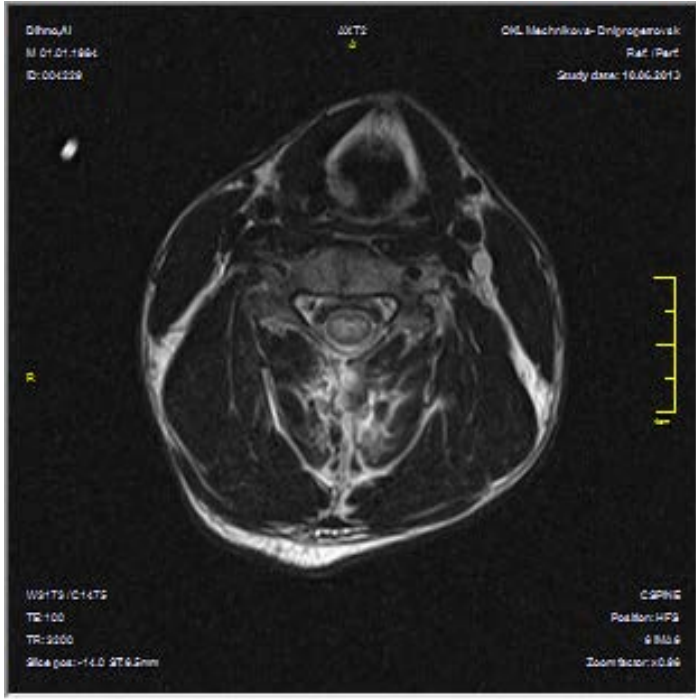

Рис. 4. МРТ исследование в Т2 ВИ, выполненное на 2-е сутки травмы. Отмечается гематома над задней продольной связкой на уровне С5-С7

Анамнез: травма произошла 09.05.13, вследствие ныряния в водоем. Вышеуказанные жалобы возникли непосредственно после травмы.

Неврологически: (ASIA - A). Нейрогенный, спинальный шок. Сознание ясное. Функция черепных нервов не нарушена. Тетраплегия, анестезия с C5, функция тазовых органов нарушена по типу задержки. Отмечается приапизм.

При поступлении выполнена спондилография, КТ шейного отдела позвоночника, диагностическая люмбальная пункция. Данных за компрессию спинного мозга не получено.

Установлен диагноз: тяжелая позвоночно-спинномозговая травма. Ушиб - гематомиелия спинного мозга на уровне С5 сегмента. Компрессионный перелом тела и дуги $\mathrm{C} 5$, тетраплегия, анестезия с уровня 
C5. Нейрогенный, спинальный шок. Механизм травмы по типу повреждения SCIWORA [4].

На 4-е сутки после травмы пациенту произведено МРТ - исследование, которое позволило выявить на фоне первичной травмы - наличие очага ушиба, обширность распространения отека спинного мозга (рис. 5, 6).

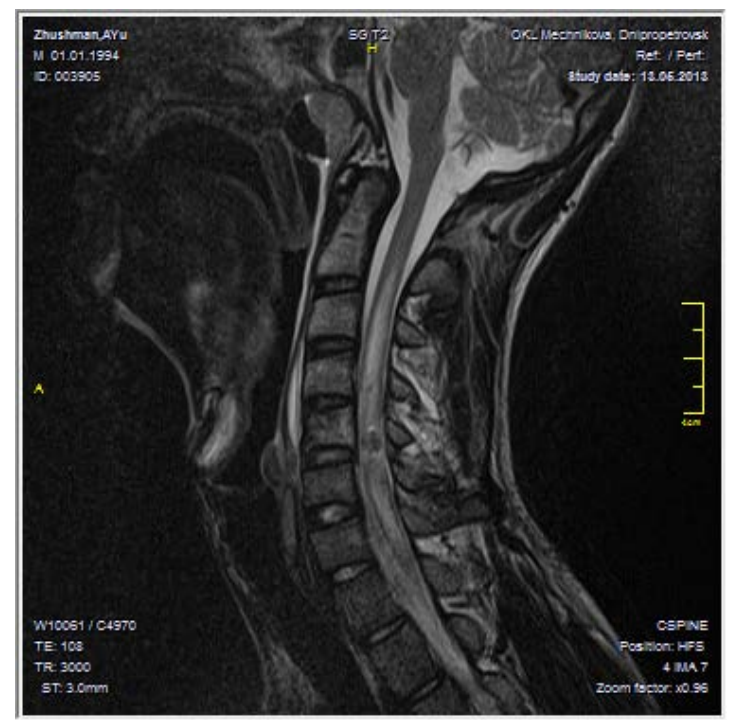

Рис. 5. МРТ исследование в Т2 ВИ, выполненное на 4-е сутки травмы. Отмечается распространение ишемии и отека на уровне С2-Д1, очаг ушиба на уровне $\mathrm{C} 5-\mathrm{C} 6$

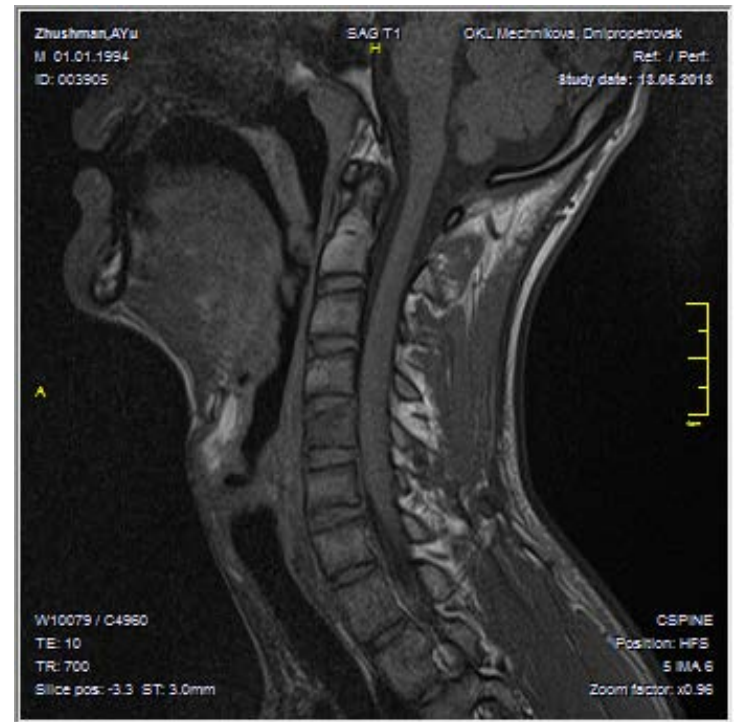

Рис. 6. МРТ исследование в Т1 ВИ, выполненное на 4-е сутки травмы. Отмечается распространение зоны ишемии и отека на уровне С2-Д1

После проведения интенсивной терапии, купирования нейрогенного, спинального шока, восстановительной терапии, через 18 дней в неврологическом статусе отмечается положительная динамика: уровень неврологических расстройств по ASIA - B, (восстановились движения в 3-х ключевых группах мышц (сгибателях и разгибателях предплечья, разгибателях кисти до 2-х баллов, уровень анестезии опустился до L3-4, отмечается чувство наполнения мочевого пу- зыря). Проведение МРТ исследования на 18-е сутки, выявляет значительный регресс отека спинного мозга, на фоне очага ушиба - гематомиелии и вторичных перифокальных изменений (рис. 7).

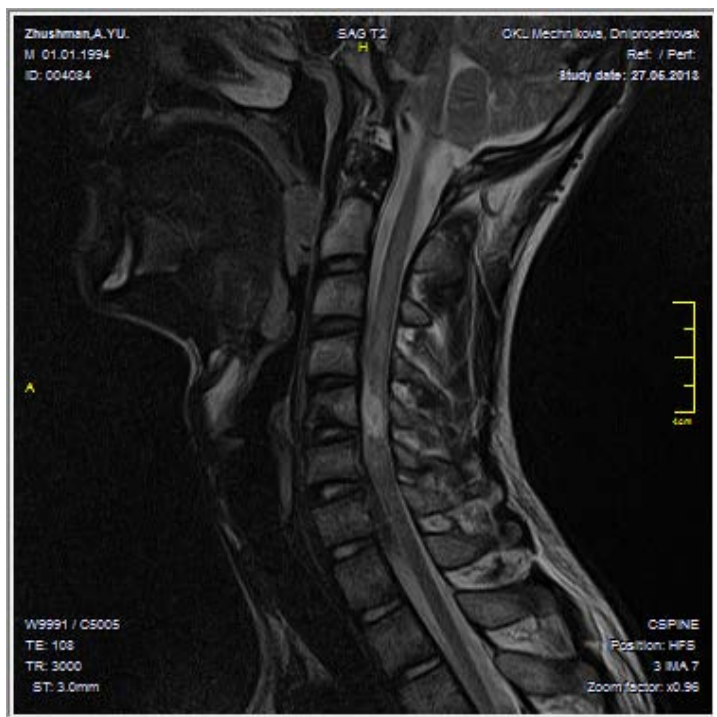

Рис. 7. МРТ исследование в Т2 ВИ, выполненное на 18-е сутки травмы. Отмечается регресс зоны отека

\section{5. Выводы}

1. Магнитно-резонансная томография является ведущим методом в диагностике отека спинного мозга, ушиба, гематомиелии, кровоизлияния.

2. Проведение исследования позволяет выявить равитие вторичных изменений в спинном мозге.

3. Метод позволяет визуализировать протяженность и выраженность повреждения спинного мозга, что обусловливает важность метода на начальном этапе лечения пациентов с позвоночно-спинномозговой травмой.

\section{Литература}

1. Труфанов, Г. Е. Лучевая диагностика травм головы и позвоночника [Текст] / Г. Е. Труфанов, Т. Е. Рамешвили. СПб. : ЭЛБИ-СПб., 2007. - 196 с.

2. Аходов, Т. А. Магнитно - резонансная томография спинного мозга и позвоночника $[$ Текст] / Т. А. Аходов, В. О. Панов, У. Айхофф. - М., 2000. - 748 с.

3. Shin, J. C. Neurologic recovery according to early magnetic resonance imaging findings in traumatic cervical spinal cord injuries [Text] / J. C. Shin, D. Y. Kim, C. I. Park, Y. W. Kim, S. H. Ohn // Yonsei Medical Journal. - 2005. Vol. 46, Issue 3. - P. 379-387. doi: 10.3349/ymj.2005.46.3.379

4. Fehlings, M. G. The optimal radiologic method for assessing spinal canal compromise and cord compression in patients with cervical spinal cord injury, II: Results of a multicenter study [Text] / M. G. Fehlings, S. C. Rao, C. N. Tator, G. Skaf, P. Arnold, E. Benzel et al. // Spine. - 1999. - Vol. 24, Issue 6. P. 605-613. doi: 10.1097/00007632-199903150-00023

5. Lammerste, D. National Institute on Disability and Rehabilitation. Neuroimaging in traumatic spinal cord injury: an evidence based review for clinical practice and research [Text] / D. Lammerste, D. Dungan, J. Dreisbach et al. // J. Spinal Cord Med. - 2007. - Vol. 30, Issue 3. - P. 205-214. 
6. Miyanji, F. Acute cervical traumatic spinal cord injury: MR imaging findings correlated with neurologic outcome prospective study with 100 consecutive patients [Text] / F. Miyanji, J. C. Furlan, B. Aarabi, P. M. Arnold, M. G. Fehlings // Radiology. - 2007. - Vol. 243, Issue 3. - P. 820-827. doi: 10.1148/ radiol. 2433060583

7. Tewari, M. K. Diagnosis and prognostication of adult spinal cord injury without radiographic abnormality using magnetic resonance imaging: analysis of 40 patients [Text] / M. K. Tewari, D. S. Gifti, P. Singh, V. K. Khosla, S. N. Mathuriya, S. K. Gupta, A. Pathak // Surgical Neurology. - 2005. Vol. 63, Issue 3. - P. 204-209. doi: 10.1016/j.surneu.2004.05.042

\section{References}

1. Trufanov, G. E., Rameshvili, T. E. (2007). Luchevaja diagnostika travm golovy i pozvonochnika. SPb.: JeLBI-SPb., 196.

2. Ahodov, T. A., Panov, V. O., Ajhoff, U. (2000). Magnitno - rezonansnaja tomografija spinnogo mozga i pozvonochnika. Moscow, 748.

3. Shin, J. C., Kim, D. Y., Park, C.-I., Kim, Y. W., Ohn, S.-H. (2005). Neurologic Recovery According to Early Magnetic Resonance Imaging Findings in Traumatic Cervical Spinal
Cord Injuries. Yonsei Medical Journal, 46 (3), 379. doi: 10.3349/ ymj.2005.46.3.379

4 Fehlings, M. G., Rao, S. C., Tator, C. H., Skaf, G., Arnold, P., Benzel, E. et. al. (1999). The Optimal Radiologic Method for Assessing Spinal Canal Compromise and Cord Compression in Patients With Cervical Spinal Cord Injury. Spine, 24 (6), 605-613. doi: 10.1097/00007632-199903150-00023

5. Lammerste, D., Dungan, D., Dreisbach, J. et al. (2007). National Institute on Disability and Rehabilitation. Neuroimaging in traumatic spinal cord injury: an evidence based review for clinical practice and research. J. Spinal Cord Med, 30 (3) 205-214.

6. Miyanji, F., Furlan, J. C., Aarabi, B., Arnold, P. M., Fehlings, M. G. (2007). Acute Cervical Traumatic Spinal Cord Injury: MR Imaging Findings Correlated with Neurologic Outcome-Prospective Study with 100 Consecutive Patients 1. Radiology, 243 (3), 820-827. doi: 10.1148/radiol.2433060583

7. Tewari, M. K., Gifti, D. S., Singh, P., Khosla, V. K., Mathuriya, S. N., Gupta, S. K., Pathak, A. (2005). Diagnosis and prognostication of adult spinal cord injury without radiographic abnormality using magnetic resonance imaging: analysis of 40 patients. Surgical Neurology, 63 (3), 204-209. doi: 10.1016/ j.surneu.2004.05.042

Рекомендовано до публікаиії д-р мед. наук, професор Дзяк Л. А. Дата надходження рукопису 14.04.2015

Сальков Николай Николаевич, кандидат медицинских наук, ассистент, кафедра нервных болезней и нейрохирургии, Днепропетровская медицинская академия, ул. Дзержинского 9, г. Днепропетровск, Украина, 49044

E-mail:salkov@ua.fm

УДК 616.36-004+616-005.6

DOI: 10.15587/2313-8416.2015.43105

\title{
ХАРАКТЕР ИЗМЕНЕНИЙ СИСТЕМЫ ГЕМОСТАЗА У БОЛЬНЫХ ЦИРРОЗОМ ПЕЧЕНИ
}

\author{
(C) А. С. Тугушев, В. В. Вакуленко, О. С. Черковская, Д. И. Михантьев, \\ В. В. Нешта, П. И. Потапенко
}

Нами исследована про- и антикоагулянтная системы в динамике у больных с компенсированным и осложненным течением заболевания.

Показано наличие тромбофилии у больных с компенсированным течением цирроза печени, что может быть одним из патогенетических факторов развития осложнений, и синдрома диссеминированного внутрисосудистого свертыввания у больных с декомпенсированным ичиррозом, что является следствием тромбофилии и причиной геморрагического синдрома

Ключевые слова: ичирроз печени, система гемостаза, коагулопатия, тромбоз, протеин C, фактор F VIII, ДВС-синдром

Since there were doubts as to the causes of hemorrhagic complications in liver cirrhosis it is actual a topical study both pro- and anticoagulant hemostasis.

Aim. To evaluate the hemostatic system in patients with liver cirrhosis.

Material and methods. 190 patients with cirrhosis were under examination: 123 have gastrointestinal bleeding, 67 - refractory ascites. 84 patients died during examination. The duration of examination was from 2-3 weeks to $2.5-3$ years.

Estimation of procoagulant unit include determining the number of platelets, prothrombin index, activated partial thromboplastin time, blood-coagulation factor F VIII, fibrinogen levels, "B” and D-dimer fibrinogen. Anticoagulant system was evaluated by activity of coagulation inhibitor of protein $C$.

Results. In $71.5 \%$ of discharged patients with bleeding and $60.0 \%$ of deaths, the activity of blood-coagulation factor F VIII exceeded normal levels. Increased activity of F VIII in patients with ascites was at $66.7 \%$ and $92.0 \%$, respectively. In the dynamics of the percentage of patients with elevated F VIII in all groups increased, reaching $85.8 \%-94.0 \%(p<0.01)$. 